\section{Biodiversity: ideas need time to mature}

Disagreements over the values of biodiversity are not a problem caused by the Intergovernmental Science-Policy Platform on Biodiversity and Ecosystem Services (IPBES) - nor are they a threat to its success (see Nature 560, 409; 2018). Such debates are grist to the mill of innovation for environmental governance.

People value the natural world in different ways. This is reflected in the 'ecosystem services' concept developed through the Millennium Ecosystem Assessment and in the 'nature's contributions to people' approach developed through IPBES. Although both global bodies have sought ways to represent diversity in their assessments, resolving or reducing diverse values has never been a stated role.

The IPBES leadership should therefore not be too hasty in seeking consensus on a single approach to representing values. The IPBES process is still aiming to improve its engagement with the humanities and social sciences (A. Larigauderie et al. Nature 532, 313; 2016), and its methodological assessment of biodiversity values started only this year. Both initiatives will catalyse new thinking. Influential ideas take time to mature.

IPBES has committed to move away from focusing solely on scientific assessment. This could achieve something more powerful than scientific consensus for biodiversity, namely a greater understanding of the terms through which humans and nature relate to one another at and across different scales.

Jasper Montana University of Sheffield, Sheffield, UK. j.montana@sheffield.ac.uk

\section{Biodiversity: guide reconciles views}

As an ecosystem-services researcher and lead author of a guide on the values of nature approved by IPBES, I am saddened by the perceived conflict in the biodiversity community over the 'ecosystem services' and 'nature's contributions to people' approaches to biodiversity valuation (see Nature 560, 423-425; 2018). Rather than being in competition, they are mutually reinforcing.

The IPBES guide (see go.nature.com/2cna2zn) makes it clear that both concepts are fully integrated into the IPBES approach. Since the guide was released, IPBES has embraced ecosystem services as one of many world views that capture how humans perceive their relationship with nature, alongside those pertaining to individuals and cultures whose conceptualization of nature leaves little room for the human-nature dualism.

Conservation is up against powerful and organized forces. Economic arguments such as avoided costs and jobs generation can influence pro-conservation decisions, as can factors such as health or indigenous and local knowledge. When former US president Barack Obama launched the US climate-change plan in 2015, he focused on the number of childhood asthma cases it would reduce, rather than on its potential economic benefits. The priority is to use all the arguments available to mobilize society's attention. Bernardo B. N. Strassburg International Institute for Sustainability and Pontifical Catholic University,

Rio de Janeiro, Brazil.

b.strassburg@iis-rio.org

\section{Biodiversity: united by a common goal}

You call on IPBES to heal "rifts" within the academic community, for example over the concepts and terminology around 'ecosystem services' and 'nature's contributions to people' (see Nature 560, 409; 2018). As chair of IPBES, I stress that both parties are united in their goal to secure a sustainable future for nature and for people.

No matter which conceptual framework is used, the message remains the same: all human societies depend on nature and on the cultural, spiritual, societal and economic benefits it provides. If the natural world continues to degrade, everyone will suffer.

IPBES recognizes that inclusive and constructive discussion is crucial for a better understanding of the global challenges we face, and for reaching a consensus on the key issues. It has therefore always embraced a diversity of views to stimulate and challenge thinking within the academic community.

Including a wide range of stakeholders, knowledge holders and decision-makers from a variety of backgrounds - geographic; gender; and disciplinary, including natural and social sciences, the humanities and people with local and indigenous knowledge - is essential for producing credible and legitimate assessments to inform decision-making.

Already, experts from a wide range of crucial programmes, projects and organizations (including those you mention) are participating in the preparation and rigorous peer review of IPBES assessments.

Robert T. Watson Potomac, Maryland, USA.

rtwatson1@gmail.com

\section{Biodiversity: debate underpins change}

We strongly object to the tone and content of your discussion on the framing and terminology used to explain the dependence of humans' wealth, health, happiness and identity on the natural world (see Nature 560, 423-425; 2018). In our view, you magnify the differences of opinion, do not do justice to the respect held for opposing advocates and oversimplify elements of the conversation.

IPBES is not in competition with the Ecosystem Services Partnership, of which R.d.G. is chair. Their debate centres on which term best serves to protect and sustainably manage the natural world: 'ecosystem services' or 'nature's contributions to people'. Both organizations have released statements that they stand united against biodiversity loss and ecosystem degradation, and that they will work together to highlight the importance of biodiversity to human well-being. Irrespective of the terminology used, our community is undivided in our knowledge that we fundamentally depend on nature in countless ways.

Debate between peers is central to scientific progress. Including the widest possible range of opinions, expertise, knowledge systems and evidence in that debate is fundamental to the systemic changes that are needed. Together, we are committed to providing all decision-makers with the best possible data and insights to inform better policies, decisions and actions on the health of the natural world we all depend on. Rudolf de Groot Ecosystem Services Partnership, Wageningen University, Wageningen, the Netherlands.

Pavan Sukhdev TEEB Advisory Board, Geneva, Switzerland. Mark Gough Natural Capital Coalition, London, UK. dolf.degroot@wur.nl

\section{CONTRIBUTIONS}

Correspondence may be submitted to correspondence@nature. com after consulting the author guidelines and section policies at http://go.nature.com/ cmchno. 